leet the canes, nox the antecedenta. I have no doubt that to the cufiened from ecarlet foror.

C10 vII. Master B. had scarlet ferer when a child, in wich he nearly died from ear and brain disease. Some months after recovery, I saw him, then perfectly deaf. The membrana tympani were both removed by ulceration, as well as the ossicula. A portion of cochlea was likewise shown me, which had escaped from the ear-copious discharge from a spongy mucous membrane. The membrane charge improved; otorrhoea lessened, and at length removed. He gradually lost his speech, and is now being educated as 2 deaf-dumb.

Case virr. A physician writes me as follows:-" My two children, aged respectively 11 and 13 , were six weeks past attacked with scarlatina anginosa, very intense and protracted; the thront affection accompanied with severe inflammation of the mucous lining of the mouth and nostrils, and spreading to the nasal ducts, and affecting the eyes. Of course the Eustachian tubes partook, and complete deafness in both cases ensued. The suppuration from the ear has been considerable and fotid, but not haring at all the smell of decaying bone; and I have accurately marked the discharge, without being enabled to detect more than a puriform discharge, acrid enough to excoriate the external ear and cheek, but unaccompanied by blood or sanies. The statement of one will serve for both, as no deviation is perceptible." I found in hoth ears of the boy that the membrana tympani was entirely removed. The malleus remained in silu, entirely stripped of its coverings, yet attached to the granulations of the mucous lining of the cavity. Otorrhoea considerable. The speech was gradually being lost; and I believe he is being taught as a deaf-mute.

The case of the sister was as nearly similar as could be. In these cases, I think there can exist little doubt that the labyrinth or the nerve in its track must be affected.

CASE X. Joseph Seamons, a.ged 9, had scarlet fever very dangerously four years ago, and has had discharge from the right ear ever since. The membrana tympani is extensively ulcerated. An abscess formed over the right mastoid process, which was insufficiently opened. A fistulous ulcer communicates between this opening and the posterior surface of the auditory meatus, from which a vascular fungus projects into the auditory canal.

CASE xI. Louisa Eames, aged 17, had scarlet-fever seven or eight years ago. A large polypus grows from the mucous lining of the tympanic cavity of each ear, and completely occupies the meatus.

Case xir. Miss M. J., aged 15, has been deaf ten or eleven years, in consequence of severe scarlet fever, which endangered her life. The deafness gradually increased, accompanied with considerable discharge of a fotid matter, of variable consistence, with formerly occasional bleeding; discharge and bleeding likewise from the nose. The general health now tolerable. The membranæ tympanorum removed by ulceration, except a small portion at the upper part. The mallei and inci both lost, and possibly also the stapedes; mucous membrane hypertrophied; meatus moderately healthy, though secreting a thin fluid; tonsils and fauces healthy.

2, Harley Street, Cavendish Square.

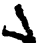

\section{NOTES AND OBSERVATIONS ON SOME OF THE MORE REMEDIABLE CASES OF DEAFNESS.}

By C. HOLTHOUSE, F.R.C.S.E., Assistant-Surgeon to the Westminster Hospital, and Lecturer on Surgical Anatomy in its Medical School.

ro. 1 .

“Ir aural diseases were as attentively studied in these kingdoms as ophthalmic or obstetric affections, then would the lengthened description of cases be unnecessary; but where do wo find throughout the whole circle of our peri- odical litorature half a dozen well observed and sccuratals noted cases of disease of the ear in a trelvemonth 1 Faithful observation and clinical records of disease are now mare ful observation and than in any other branch of medical ecience." Fully concurring in the opinion thus expresed science. by one of the ablest aurists of the present day (Mr. Wildo), trusting that they may in some measure supply this want. They are plain and faithful records of what I actually saw and observed; nothing is stated on mere conjecture; when I have fairly scen a part, I have described as accurately as possible its appearance; if an unsatisfactory view was potained, I hare stated so in the notes. Every case, therefore, as far as it goes, may be relied on for accuracy; the truth has always been told, though possibly not the whole truth, because the necessary examinations to arrive at it, either could not be made, or, having been made, the information sought for could not in every instance even then be obtained.

It may be thought by some that the researches of Mr. Toynbee in the department of aural surgery have made us so fully acquainted with the pathology of diseases of the ear, that further illustrations are unnecessary.

Without, however, any disparagement to this distinguished aurist, the value of whose labours no one can appreciate more fully than myself, I must observe, that hitherto they have been confined almost exclusively to an elucidation of the morbid changes found in the ear after death; while the symptoms which these changes gave rise to during life, the exact amount of deafness which this or that lesion occasioned, we are left in ignorance of. The association of the symptoms with the lesions is, therefore, still a desideratum, which it is hoped this contribution may furnish. In many of the cases reported, there will be found the identical changes in the organ of hearing, which Mr. Toynbee's dissections have revealed; while data are supplied relative to the amount of improvement of which the diseased organ is susceptible.

CASE I. Acute Inflannmation of the Membrana Tympani of both Ears brought on by Cold; Great Deafness, Severe Pain, Loud Tinnitus, followed on the second day by discharge; Right Membrana Tympani covered with Florid Granulations; Left Ecchymosed; Eustachian. Tube of the Left Lar obstructed; Treatment by Leeches, Blisters, Aperients, and afterwards an Astringent Lotion; Hearing restored. John Bradford, aged 46 years (cook), applied to me on the 14th July, for relief from a purulent discharge affecting both ears, and accompanied with pain, a high decree of deafness, and a constant buzzing and ticking tinnitus. On washing away the discharge, by means of a syringe, the membrana tympani of the left ear was less lucent than in the healthy state, but was otherwis? not remarkable; the membrana tympani of the right ear could remarkable; the membrana tympani of the right ear could to detach with the syringe; on gently touching it, however, with a probe, great pain was excited.

History. Eight days ago he caught cold, which, as he said, "stopped up his ears". This was soon followed by severe pain in both ears, accompanied by a humming and blowing, and various odd sounds. The pain continued to increase in severity, when it was considerably relieved by a discharge, which broke forth from both ears on the second day of the pain, just after the application of some leeches; the buzzing and deafness, however, remained undiminished. When the tinnitus first came on, and for some time afterwards, he could not dispossess himself of the idea that the noises proceeded from without; and the delusion was so me see whence they proceeded. He said that he had enjoyed good health; but thirty years ago he had a similar attack, which was got rid of without impairment to hearing.

Hirudines vi, pone aures sing. statim applic.

Habeat haust. cathart. omni mane.

July 15th. The leech-bites bled freely, and the patient was much relieved. He felt lighter in the head, and slept better last night than he had done since the attack. 
It dibehnrge from the left ear had ceased, and the hearing was considerably improved; but the busxing and ticking remained. I was still unable to procure a view of the right membrana tympani.

July 17th. He continued to improve: the hearing was considerably better, and the discharge had ceased in both ears; the buzzing was fainter, but the ticking remained. He slept, and felt well. The day being bright, I obtained an excellent view of both membrano tympani; that of the right was entirely altered in colour and appearance. Instead of being smooth, translucent, and shining, its surface was irregular, highly vascular, and had exactly the appearance of a granulating ulcer. The left membrane was less diseased; it had lost its translucency, was partly red and Jellow; the former arising from ecchymosis; the latter from a layer of lymph on its surface. Repetatur mistura.

Imponatur emplastrum vesic. pone aures sing.

July 19th. The blisters had risen well; but, from the pain they occasioned, prevented the patient sleeping; and this morning he complained of being languid and low. The hearing continued to improve, and the humming and ticking were much fainter: the latter sometimes entirely ceased. The membraua tympani of the right ear had lost its moist, vascular, granulating surface; and was dry and smooth, rather shining, and of a flesh colour; not yet presenting the appearance of membrane, being obviously thickened, and its colour arising from the red vessels traversing it. Corresponding with the projection of the handle of the malleus were the remains of granulating papillæ. The left membrana tympani was smooth and dry, but less shining, and of a darker colour than natural; which was produced by red vessels traversing it, and which can be distinctly perceived.

July 22nd. IIe continued to improve; his hearing had increased, and the tinnitus diminished. The membrana tympani of the right ear presented much the same appearance as at the last visit, but had lost the red central projection; that of the left, as far as the light would admit of its being seen, appeared to have regained nearly its natural appearance.

July 26 th. The deafness, though not entirely gone, was not perceptible in conversation; and the tinnitus had diminished to a slight buzzing. The membrana tympani of the right ear had lost its flesh colour, but had not recovered its translucency, having an opaque, dirty, yellowish white appearance. On parts of its surface, some remains of dry blood were visible. The projection caused by the short process of the malleus could be seen, but not the handle of this bone, owing to the thickening of the membrane. A vascular swelling had made its appearance on one part of the circumference of the left membrana tympani; and, on touching this swelling with the probe, great sensibility was evinced. On conversing with him to-day, he informed me that he has been subject to ear-ache with discharge, more frequently with the right than the left ear; and the attack which he mentioned having suffered from thirty years ago was only the first in his recollection. Notwithstanding the more frequent attacks of the right ear, he heard better with it than with the other.

Applicatur lotio zinci sulphatis.

August 11th. The lotion prescribed in the last note, mixed with an equal quantity of hot water, had been injected into each ear, night and morning; and to-day he came to thank me, considering himself quite well. He still had occasional noises in the left car, and did not hear so well with it as the other; a watch held opposite this, was but just heard at a distance of four inches, while the other ear distinguished it at a distance of forty inches. On closing the mouth and nostrils, and expiring strongly, no sensation was produced on the left side; while the air passing through the Eustachian tube, and into the tympanum of the right, caused some pain. The day was too dull to admit of a satisfactory examination of the membranæ; but as far as could be seen they appeared nearly healthy.

REXARKS. The inflammatory appearances presented by the

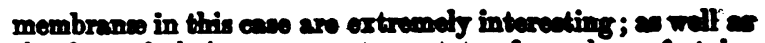
the fact of their recovery to a stato of nearly perfeot integrity, notwithstanding the serere character of the inflammation, and the repeated attacts from which the patient had previously suffered. It is deserving of remart that the hearing was better in the right ear than in the left, notwithstanding the more frequent attacks to which it had been subject, and the more diseased appearance of its membrana tympani: this was probably owing to the patent condition of the Eustachian tube of the side, while that of the opposite was either temporarily or permanently closed.

Mr. Wilde, in his excellent work on Aural Surgery, is the only writer I have met with who makes mention of the peculiar appearance sometimes presented by the membrana tympani, of which the right ear in this patient affords an example. "In some instances," observes Mr. Wilde, "the whole surface (of the membrane) was not only of a deep red, but also granular, like that of a ripe raspberry, or, the appearance so frequently presented on the inside of the upper eyelid,-such were cases of long continued otorrhoes." The case just reported would show that there is no necessary connection between the condition of the membrana tympani just described, and a long continued otorrhoea.

[To be continued.]

9, New Burlington Strcet.

\section{$\sqrt{1}$ \\ ON THE ORIGIN AND TREATMENT OF CHRONIC DISEASES OF THE SKIN.}

By THOMAS HUNT, F.R.C.S., Surgeon to the Western Dispensary for Diseases of the Skin.

$$
\text { No. } 111 \text {. }
$$

HAVING made some observations on the general principles of treatment, and having alluded to the constitutional origin and complications of cutaneous diseases, I proceed to exemplify by cases, selected chiefly from dispensary practice, shewing how these principles are applicable to the different orders and genera in which these diseases were classed by Drs. Willan and Bateman. In so doing, I shall not dwell minutely on the anatomy of the skin, as my object is wholly practical; and the practice, in order to be successful, must be directed rather to the internal or general cachexia manifested by the eruption, than to the particular structure involved in the disease.

$$
\text { ORDER I.-PIMPLES (PAPULE). }
$$

When a pimple, or cluster of pimples, occurs, containing no fluid, shewing no tendency to suppuration, and terminating in no result, except a particle of scurf at the apex of the pimple, the disease belongs to the order papulae.

The Dis thosis ought, therefore, to be simple and easy. But cases occur in which, if some of the pimples contain no fluid, others contain pus or serous matter; and in the more severe forms of lichen, fluid enough is discharged to produce a crust which conceals the original papulæ, and the case may be mistaken for cczema or psoriasis. Thus papulous diseases are easily mistaken for vesicular, tubercular, or even pustular and squamous affections. Again, in severe prurigo, the pimples being of the colour of the skin, and the apex being generally flat or truncated, nothing appears but marks of the patient's nails and little black spots, which are the dried blood discharged by the wounding of the pimples. Moreover, lichen is often complicated with urticaria, which altogether masks the original form, and indeed presents a new and important indication in the treatment. Lichen is also very liable to be mistaken for scabies.

The Progyosis is as various as the cases presented. Strophulus, the infant form of lichen, soon gets well, with or without appropriate treatment. Lichen, when it occurs in the face, is extremely difficult of treatment, especially in middle aged females, who are the most frequent victims. 